\title{
Avaliação microbiológica, fisíco-química de águas minerais comercializadas em Vitória da Conquista
}

\author{
Microbiological, physical and chemical assessment of mineral waters sold in vitória da Conquista \\ Isabel Celeste Caires Pereira Gusmão' \\ 'Bióloga, Faculdade Independente do Nordeste, Vitória da Conquista, Brasil
}

\begin{abstract}
Resumo
Com a dúvida sobre a qualidade da água de abastecimento público, o cidadão passou a utilizar a água mineral com maior intensidade. O objetivo desta pesquisa foi avaliar aspectos de qualidade microbiológica em amostras de água mineral natural, em garrafas individuais de duas marcas comercializadas na cidade de Vitória da Conquista-Ba. Foram utilizadas dez amostras provenientes de duas marcas. As amostras foram adquiridas aleatoriamente, em épocas e estabelecimentos diferentes para que fossem originadas de lotes diversos. Para análise de coliformes totais e coliformes fecais/E. coli utilizou-se a técnica (NMP) determinação de número mais provável. Para contagem de bactérias heterotróficas, foi utilizada a técnica de cultivo em profundidade. Todas as amostras de todas as marcas (100\%) apresentaram ausência de coliformes fecais/E.coli sete amostras (70\%) das duas marcas apresentaram contagens acima de $500 \mathrm{UFC} / \mathrm{mL}$ para bactérias heterotróficas apresentando um desacordo segundo a legislação brasileira para águas minerais que estabelece o limite de $500 \mathrm{UFC} / \mathrm{mL}$ para água de consumo humano proveniente de sistemas de abastecimento público.
\end{abstract}

Palavras chave: Água mineral, contaminação bacteriana, coliformes.

\begin{abstract}
With the doubt on the quality of the water of public supplying, the citizen started to use the mineral water with bigger intensity. The objective of this research was to evaluate aspects of microbiological quality in natural mineral water samples, in individual bottles of two marks commercialized in the city of Vitória da Conquista. Ten samples proceeding from two marks had been used. The samples had been acquired randomly, at different times and establishments so that they were originated from diverse lots. For analysis of coliformes total and coliformes fecais/E. coli used it technique (NMP) determination of most likely number. For counting of heterotróficas bacteria, the technique of culture in depth was used. All the samples of all the marks (100\%) had presented absence of coliformes fecais/E.coli seven samples (70\%) of the two marks had presented 500 countings above of $\mathrm{UFC} / \mathrm{mL}$ for heterotróficas bacteria presenting a disagreement in accordance with the Brazilian legislation for mineral waters that the limit of 500 establishes $\mathrm{UFC} / \mathrm{mL}$ for water of human consumption proceeding from systems of public supplying.
\end{abstract}




\section{INTRODUÇÃO}

A água constitui um dos elementos fundamentais para a existência do ser humano. Em seu estado natural é um dos componentes de maior pureza que se conhece e, atualmente, torna-se difícil encontrar uma fonte de água doce que não tenha suas características alteradas.

A água contém uma série de micro-organismos, alguns naturais do ecossistema aquático e outros micro-organismos transitórios, provenientes do solo e de dejetos industriais e domésticos como, por exemplo, Clostrídios, Pseudomonas aeruginosa, Enterococos (MACÊDO, 2004).

Para a avaliação das condições de potabilidade de uma água utilizam-se bactérias do grupo coliforme, que atuam como indicadores de poluição fecal, pois estão sempre presentes no trato intestinal humano e de outros animais de sangue quente, sendo eliminadas em grande número pelas fezes. A presença de coliformes na água indica poluição com o risco potencial da presença de micro-organismos patogênicos e sua ausência é evidência de uma água bacteriologicamente potável, uma vez que são mais resistentes na água que as bactérias patogênicas de origem intestinal.

A água mineral natural, geralmente, apresenta excelente qualidade microbiológica, uma vez que, devido ás características naturais dos aquíferos, ela permanece protegida de praticamente todos os riscos de poluição. De acordo com a Organização Mundial da Saúde, cerca de $80 \%$ de todas as doenças que acometem os países em desenvolvimento provêm da água de má qualidade. As doenças de veiculação hídrica, como febre tifóide, cólera, salmonelose, shiguelose, poliomielite, hepatite A, verminoses, são predominantemente resultantes do ciclo de contaminação fecal/oral e têm sido responsáveis por vários surtos epidêmicos, representando causa de elevada taxa de mortalidade em indivíduos com baixa resistência imunológica (Freitas et al,2001).

Tendo em vista todas essas evidências de contaminação, o presente trabalho tem como objetivo avaliar a qualidade microbiológica da água quanto à presença de coliformes totais e fecais, Clostridios

Sulfito Redutores, Enterecocos e Pseudomonas aeruginosa bem como o estudo das condições físicoquímica de duas marcas de águas minerais comercializadas na cidade de Vitória da Conquista, Bahia.

\section{METODOLOGIA}

\section{I Amostragem}

Foram utilizadas 20 amostras de água mineral natural de 20 litros, embaladas em garrafas para uso individual, provenientes na cidade de Vitória da Conquista - BA. As amostras foram adquiridas em vários estabelecimentos no comércio da cidade de, forma aleatória e em períodos diferentes, sendo de 2 marcas comercializadas sem a preocupação com a data de embalagem, mas observando-se o prazo de validade simulando as condições do consumidor. As amostras foram retiradas diretamente dos garrafões, adequadamente higienizados, tomando-se cuidados para não contaminá-las e foram transportadas diretamente ao laboratório de Microbiologia da FAINOR dentro de uma caixa térmica. As análises foram realizadas mensalmente. O período de estudo se deu de fevereiro a junho de 2013.

\subsection{PARÂmetros}

Os micro-organismos pesquisados são todos exigidos pela Resolução RDC N²75, de 22 de setembro de 2005, do Ministério da Saúde exceto Clostrídeos Sulfito Redutores (NMP /100mL).

\subsection{ANÁLISE MICROBIOLÓGICA}

As análises microbiológicas foram realizadas no Laboratório de Microbiologia da FAINOR. Foram avaliados os seguintes parâmetros: coliformes totais, coliformes fecais/E.coli bactérias heterotróficas, Clostridios Sulfito Redutores, Enterecocos e Pseudomonas aeruginosa.

\subsection{DeterminAÇÃo do NÚMERO MAIS PROVÁVEL (NMP) DE COLIFORMES TOTAIS E COLIFORMES TERMOTOLERANTES.}

Para a identificação da Escherichia coli, como indicador biológico, pode-se usar o Caldo EC, para contagem por "Número Mais Provável" por mililitro (NMP/mL), que é seletivo para micro-organismos Gram negativos em função da presença de sais biliares. A incubação à temperatura de $45,5^{\circ} \mathrm{C}$ em banho-maria por 24 horas permite evidenciar a presença de coliformes fecais, pois eles apresentam a capacidade de fermentação da lactose com produção de gás a temperaturas mais elevadas. 
Em seguida foram realizadas as diluições seriadas, retirando $01 \mathrm{~mL}$ da amostra e transferindo-o para um tubo de ensaio contendo $9 \mathrm{~mL}$ de solução salina $0,8 \%$ e, em seguida foi transferido $01 \mathrm{~mL}$ (deste tubo) para outros tubos até completar as três diluições (10-1, 10-2 e 10-3), conforme a IN 62/ Mapa (Brasil, 2003).

Foi transferido $01 \mathrm{~mL}$ de cada tubo de cada diluição para cada um dos três tubos contendo 09 $\mathrm{mL}$ de caldo Lactosado EC, adicionado o tubo de Durhan (invertido) com função de coletar o gás produzido durante a fermentação (Macêdo, 2004). Por esta técnica se pode obter informações sobre a população presuntiva de coliformes (teste presuntivo); sobre a população real de coliformes (teste confirmativo) e sobre a população de coliformes de origem fecal (Macêdo, 2004) .

Como citado, o ensaio se processa através de 2 etapas (ensaio presuntivo e confirmativo) de realização obrigatória para todos os tipos de amostras de água, as quais são complementadas, quando indicado, por uma terceira etapa (ensaio completo). A densidade de coliformes fecais é obtida a partir de um ensaio específico, aplicado paralelamente ao teste para confirmação de coliformes totais.

\subsection{Pesquisa de Clostrídios sulfito- Redutores}

Empregou-se nessa análise o Meio Reforçado para Clostrídios (Difco ${ }^{\circledR}$ ) e incubação a $45^{\circ} \mathrm{C}$ por 48 horas em jarra de anaerobiose contendo gerador de anaerobiose (Silva et al., 2005).

\subsection{Pesquisa de EnTERococos}

Como teste presuntivo, eram inoculados volumes de $10 \mathrm{ml}$ da amostra a ser analisada em cada tubo de uma serie de 10 tubos contendo Caldo Azida- dextrose em concentração dupla. Posteriormente, incubavam os tubos a $35^{\circ} \mathrm{C}$ por 48 horas. A presença de Enterococos é indicada pela presença de gás, retido nos tubos de Durhan. Os tubos positivos eram, então, confirmados por repicagem (com uma alçada) em placas contendo Ágar m-enterococos. A presença de pequenas colônias rosadas confirmava a contaminação por Enterococos.

\subsection{Pesquisa de Pseudomonas aeruginosa}

O NMP de P. aeruginosa foi realizado utilizando-se a técnica dos tubos múltiplos contendo Caldo Asparagina, meio seletivo no qual a asparagina é a única fonte de carbono e nitrogênio disponível para crescimento da bactéria, como citado por Cabrini e Gallo (2001). Os resultados positivos foram repicados para uma placa de Ágar Cetrimide incubada a $35^{\circ} \mathrm{C}$ por $48 \mathrm{~h}$. O surgimento de coloração esverdeada em toda a placa ou de colônias verde limão indicou resultado positivo para a presença de Pseudomonas aeruginosa segundo Cabrini e Gallo (2001). Os resultados positivos foram repicados para uma placa de Ágar Acetamida incubada a $35^{\circ} \mathrm{C}$ por $48 \mathrm{~h}$. O surgimento de coloração esverdeada em toda a placa ou de colônias verde limão indicou resultado positivo para a presença de Pseudomonas As cepas positivas foram repicadas para placas de Ágar Leite e incubadas a $35^{\circ} \mathrm{C}$ por $48 \mathrm{~h}$ para se confirmar a presença de P. aeruginosa e observar a formação de um halo claro ao redor das colônias e a produção de um pigmento verde, em seguida anotar o número de placas confirmadas e determinar o número mais provável (NMP) de Pseudomonas aeruginosa na amostra utilizando uma tabela NMP adequada.

\subsection{ANÁLISE DO PH}

Foi utilizado para essa análise, o pHmetro da marca Quimis, modelo Q400A. O pH de cada amostra foi verificado em triplicata com auxílio de pHmetro. O resultado obtido correspondeu à média aritmética das três aferições, para cada amostra. Além do $\mathrm{pH}$, foi analisado o cloro, dureza e condutividade de cada amostra.

\section{RESULTADOS E DISCUSSÕES}

De acordo com a Tabela 1 verifica-se que todas as amostras das duas marcas (100\%) atenderam ao padrão para coliformes fecais/E.coli, ou seja, ausência deste grupo microbiano. Esses resultados também foram observados nos estudos realizados por Cabrini e Gallo (2001); Coelho et al. (1998); David, (1999); Eiroa et al. (1996); Nascimento,(2000); Reis et al. (2006); Sabioni e Silva (2006).

A enumeração de coliformes fecais/E. coli é importante, pois sua presença indica a possibi- 
lidade de ocorrência de outros micro-organismos patogênicos entéricos na água e a possibilidade de contaminação fecal. Por outro lado, alguns sorotipos de E. coli são responsáveis por gastrenterites, tendo a diarréia como o principal sintoma. (Santana, 2003).

Os valores de $\mathrm{pH}$ condutividade e bicarbonato apresentaram com uma pequena diferença do exposto no rótulo. Os resultados para cloretos estavam acima dos valores apresentados no rótulo enquanto que os parâmetros de cálcio, magnésio, potássio, sulfato e sódio estavam aquém dos valores indicados nas embalagens. Os resultados do presente trabalho permitem concluir que: $65 \%$ das amostras analisadas estavam em desacordo com os padrões microbiológicos legais apresentando contaminação por bactérias heterotróficas sugerindo condições higiênicas- sanitárias deficientes (Tabela2).

Entretanto, resultado negativo de coliformes fecais não significa ausência de contaminação fecal, porque esse resultado é influenciado pelo número e tamanho da amostra, sensibilidade da metodologia, quantidade presente de coliformes, interação sinérgica com Pseudomonas aeruginosa, além de haver cepas de Salmonella mais resistentes do que os coliformes (Santana, 2003).

Das duas marcas analisadas, 6 amostras (60\%) apresentaram contagens elevadas ( $>500 \mathrm{UFC} /$ $\mathrm{mL}$ ) para bactérias heterotróficas (Tabela 1), estando em desacordo com o padrão utilizado como base nesta pesquisa, que estabelece o limite de $500 \mathrm{UFC} / \mathrm{mL}$ para água de consumo humano proveniente de sistemas de abastecimento público. Esses resultados positivos em $60 \%$ das amostras são superiores aos encontrados por Cabrini e Gallo (2001) em 38\% das amostras, Reis et al. (2006) em 20\%; Sabioni e Silva em 50\% (2006)

A maioria das bactérias heterotróficas, geralmente, não é patogênica. Entretanto alguns membros desse grupo, incluindo Legionella spp., Micobacterium spp., Pseudomonas spp., Aeromonas spp., podem ser patógenos oportunistas segundo Reis et al. (2006)

Como as águas minerais engarrafadas são consumidas sem qualquer tratamento, contagens elevadas de heterotróficos podem indicar a possível presença de patógenos, especialmente formas resistentes a múltiplos antibióticos, o que pode representar sério risco a saúde de indivíduos imunocomprometidos (Jeena et al., 2006).

Os micro-organismos heterotróficos presentes na água, quando em grande número, além de representarem um risco à saúde, podem ocasionar outros problemas, tais como: deterioração da qualidade da água, com desenvolvimento de odores e sabores desagradáveis e, ainda, formação de limo ou películas. Estudos realizados revelaram que quando a contagem deste grupo aumenta até um nível de $500 \mathrm{UFC} / \mathrm{mL}$, a frequência na detecção de coliformes também aumenta; porém, quando a população bacteriana excede a $1000 \mathrm{UFC} / \mathrm{mL}$, a frequência na detecção de coliformes decresce (Jena et al.,2006).

A maioria das amostras analisadas neste trabalho apresentou contagem de heterotróficos acima de $1000 \mathrm{UFC} / \mathrm{mL}$, o que pode representar a inibição da deteç̧ão de coliformes e, consequentemente, a possível presença de contaminação fecal e de enteropatógenos. A contagem de bactérias heterotróficas em águas minerais deve ser realizada com o objetivo de avaliar as condições higiênico-sanitárias do sistema industrial (Sabioni 2006).

Devido aos problemas causados pelas altas contagens de heterotróficos em água mineral, e para se avaliar as condições higiênico-sanitárias do sistema industrial, seria interessante a inclusão desse parâmetro na legislação brasileira para água mineral de forma a fornecer água mais segura para o consumidor. No entanto, o fato da água mineral apresentar micro-organismos autóctones que variam conforme a fonte e se multiplicam após o engarrafamento, dificulta o estabelecimento de limites.

De acordo com Morais e Costa (1990), as características das fontes influenciam a população bacteriana das águas minerais. No entanto, limites sugeridos de $500 \mathrm{UFC} / \mathrm{mL}$ para água mineral são problemáticos, já que a água de diferentes fontes terá diferentes quantidades de matéria orgânica.

Segundo Eiroa et al (1996) a primeira medida seria melhorar as condições higiênicas do pessoal, das embalagens e tampas e dos equipamentos usados no processo de engarrafamento, com isso, além de diminuir a quantidade de matéria orgânica que entra em contato com a água e assim possivelmente reduzir a população dos micro-organismos autóctones, também evita-se contaminações. A multiplicação dos micro-organismos em água engarrafada se dá devido ao contato com compostos orgânicos, que podem estar presentes em tubulações, reservatórios ou nas embalagens e tampas.

Das 20 amostras avaliadas, 13(65\%) apresentaram-se contaminadas por bactérias heterotróficas estando em desacordo com os padrões microbiológicos estabelecidos pela RDC 518/2004 Pseudomonas, E.coli, Enterococos e Clostrídios sulfito redutores não foram isolados em nenhuma das amostras. (Tabela 1) 
Tabela 1 Ocorrência dos micro-organismos pesquisados nas 02 marcas de água mineral analisadas

\begin{tabular}{|c|c|c|c|c|c|c|}
\hline Marcas & $\begin{array}{c}\text { Coliformes } \\
\text { totais }\end{array}$ & $\begin{array}{c}\text { Coliformes } \\
\text { fecais }\end{array}$ & $\begin{array}{c}\text { Bactérias } \\
\text { heterotróficas }\end{array}$ & Enterococos & Paeruginosa & $\begin{array}{c}\text { Clostridium } \\
\text { Sulfito } \\
\text { redutor }\end{array}$ \\
\hline A & - & - & + & - & - & - \\
\hline A & - & - & + & - & - & - \\
\hline A & - & - & + & - & - & - \\
\hline A & - & - & + & - & - & - \\
\hline A & - & - & + & - & - & - \\
\hline A & - & - & + & - & - & - \\
\hline A & - & - & + & - & - & - \\
\hline A & - & - & + & - & - & - \\
\hline A & - & - & + & - & - & - \\
\hline A & - & - & + & - & - & - \\
\hline B & - & - & + & - & - & - \\
\hline B & - & - & + & - & - & - \\
\hline B & - & - & + & - & - & - \\
\hline$B$ & - & - & + & - & - & - \\
\hline B & - & - & + & - & - & - \\
\hline$B$ & - & - & + & - & - & - \\
\hline B & - & - & + & - & - & - \\
\hline B & - & - & + & - & - & - \\
\hline B & - & - & + & - & - & - \\
\hline B & - & - & + & - & - & - \\
\hline
\end{tabular}

(+): presente; (-): ausente

Em relação à qualidade físico química, os diferentes tipos de águas minerais apresentam as seguintes características: em relação à dureza, as amostras de água mineral apresentaram valores menores de 50mg/L de CaCO3) ( Tabela 2).

Todas as amostras apresentaram qualidade satisfatória no que se refere à contaminação por Enterococos,Clostridios sulfito-redutores e Pseudomonas aeruginosa.(Tabela1). Deve-se conduzir o 
processamento, embalagem e estocagem da água mineral sob rigorosas práticas higiênicas, de forma a minimizar a contaminação microbiológica do produto.

Estudos realizados por Eiroa et al. (1996) em amostras de água mineral em temperatura ambiente, encontraram um aumento da população dos micro-organismos heterotróficos nos primeiros 30 dias de armazenamento para depois diminuir, de maneira irregular, e ficar aproximadamente constante até completar 6 meses de observação. Uma medida para prevenir isso seria o armazenamento em baixas temperaturas nos mercados e nas casas, o que diminuiria a multiplicação dos autóctones e impediria a multiplicação dos patogênicos; também poderia ser utilizado o binômio tempo/temperatura, diminuindo a temperatura e o tempo de estocagem, podendo retardar a multiplicação microbiana.

Nos estudos feitos por Cabrini e Gallo (2001) foi observado que todas as amostras de $500 \mathrm{~mL}$ apresentaram elevadas contagens de heterotróficos, o que sugere maiores cuidados com relação às condições higiênicas das garrafas utilizadas, principalmente as de pequeno volume, a fim de assegurar a boa qualidade do produto.

Para Coelho et al ( 1998) estudos têm mostrado que as bactérias geralmente ocorrem em maior número nas garrafas plásticas do que nas de vidro, isso ocorre devido à característica do plástico em permitir a passagem de $\mathrm{O} 2$. Os nutrientes liberados do plástico são também um possível contribuinte para o aumento da multiplicação bacteriana na água (Rosenberg, 2003).

Rosemberg, (2003) concluíram que a principal causa das baixas contagens de colônias da mesma água mineral em garrafas de vidro mecanicamente limpas diferenciando-se das garrafas plásticas, com altas contagens de colônias, é o efeito bacteriostático dos agentes de limpeza residual. O uso de garrafas de vidro pode ser uma alternativa para melhorar a qualidade das águas minerais.

Tabela 2- Análise físico - química na determinação da qualidade da água dos tipos A e B

\begin{tabular}{|l|c|c|c|c|}
\hline $\begin{array}{l}\text { Valores da } \\
\text { pesquisa }\end{array}$ & & & $\begin{array}{l}\text { Valores do } \\
\text { rótulo }\end{array}$ & \\
\hline AMOSTRAS & $\mathrm{A}$ & $\mathrm{B}$ & $\mathrm{A}$ & $\mathrm{B}$ \\
\hline $\mathrm{pH}$ & 5,8 & 5,2 & 4,87 & 4,33 \\
\hline Condutividade & 29 & 80 & 50 & 79 \\
\hline Cloreto & 39,8 & 61,5 & 8,82 & 13,15 \\
\hline Dureza & 18,3 & 19,1 & - & - \\
\hline Cálcio & 0,025 & 0,075 & 0,161 & 0,311 \\
\hline Magnésio & 0,05 & 0,075 & 1,243 & 1,244 \\
\hline Potássio & 0 & 0 & 1,853 & 0,405 \\
\hline Sódio & 0,17 & 0,55 & 5,133 & 11 \\
\hline $\begin{array}{l}\text { Alcalinidade } \\
\text { Total }\end{array}$ & 3,35 & 2,5 & & - \\
\hline Sulfato & 0 & 0 & 1,18 & 1,5 \\
\hline
\end{tabular}

\section{CONCLUSÕES}

Constata-se, assim, que apesar dos parâmetros físico-químicos estarem dentro dos padrões de potabilidade, necessita-se de uma reavaliação dos rótulos em relação às quantidades dos sais analisados e que todas as amostras apresentaram ausência de crescimento microbiano. 


\section{REFERÊNCIAS}

Brasil 2003. Ministério da Saúde. Agência Nacional de Vigilância Sanitária. Programa Nacional de Monitoramento da Qualidade Sanitária de Alimentos. Resultado da 2a . Etapa/ Água Mineral. Disponível em: http:// www.anvisa.gov.br/alimentos/programa/etapa2/categorias/agua.htm Acesso em 21/06/2010.

CABRINI, K. T.; GALLO, C. R. Avaliação da qualidade microbiológica de águas minerais envasadas. Higiene Alimentar., v.15, n.90/91, p.83-92, 2001.

COELHO, D. L.; PIMENTEL, I. C.; BEUX, M. R. Uso do método cromogênico para quantificação do NMP de bactérias do grupo coliforme em águas minerais envasadas. B. CEPPA, v.16, n.1, p.45-54, 1998.

COMPANHIA DE TECNOLOGIA DE SANEAMENTO AMBIENTAL. Contagem padrão de colônias de bactérias. São Paulo, 1978. 11p. (Normalização Técnica - L5.201).

DAVID, P. R. B. S. Avaliação da qualidade microbiológica de águas minerais e de abastecimento de alguns pontos da cidade do Recife, PE. Higiene Alimentar.,v.13, n.60, p.36-42, 1999.

EIROA, M. N. U.; JUNQUEIRA, V. C. A.; SILVEIRA,N. F. A. Avaliação microbiológica de linhas de captação e engarrafamento de água mineral. Ciência e Tecnoligia Alimentar, v. 16, n. 2, p. 165-169, 1996.

Freitas, M.B.; Freitas, C.M. A vigilância da qualidade da água para consumo humano - desafios e perspectivas para o Sistema Único de saúde. Ciência \& Saúde Coletiva, 2001

JEENA, M. I. Risk assessment of heterotrophic bacteria from bottled drinking water sold in Indian markets. Int. J. Environmental Health, v. 209, p.191-196, 2006

MACÊDO J. A. Águas \& Águas. 2. ed. Atual e rev São Paulo, 2004

Morais P.V, COSTA M.S. Alterations in the major heterotrophic bacterial populations isolated from a still bottled mineral water. J Applied Bacteriologica 69: 750-757, 1990

NASCIMENTO, A.R.Qualidade microbiologica das águas minerais consumidas na cidade de São Luis. Revista Higiene Alimentar 14 (76): 69-72, 2000

ROSENBERG, F. A. The microbiology of bottled water. Clinica Microbiológica Newslett., New York, v. 25, p.41-44, 2003

REIS, J. A.; HOFFMANN, P.; HOFFMANN, F. L. Ocorrência de bactérias aeróbias mesófilas, coliformes totais, fecais e Escherichia coli, em amostras de águas minerais envasadas, comercializadas no município de São José do Rio Preto, SP. Higiene Alimentar., v.20, n.145,p.109-116, 2006

SABIONI, J. G.; SILVA, I. T. Qualidade microbiológica de águas minerais comercializadas em Ouro Preto, MG. Higiene Alimentar., v.20, n.143, p.72-78, 2006

SANT'ANA, R.C.Qualidade Microbiológica de águas minerais. Ciência Tecnológica

Alimentar. Campinas, 23: 190-194, dez. 2003. Disponível em<http://www.scielo.br/pdf/cta/v23s0/19495. pdf>. Acesso em: 02/06/20013 